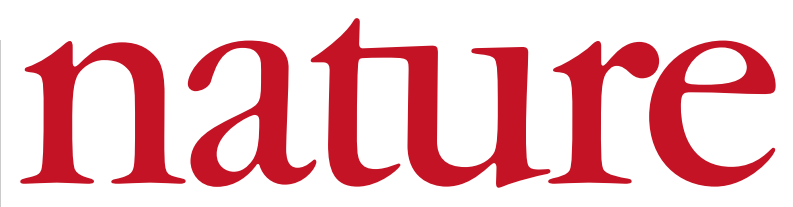

30 September 2004 Volume 431 Issue no 7008

\title{
Holding the line at NASA
}

Space-based astronomy in the United States is under threat thanks to a misplaced sense of priorities within government. Researchers should take every opportunity to resist and to make the most of support from Congress.

$\mathrm{F}$ or the past decade, a firewall has existed within NASA's budget, separating the agency's science programme from its astronaut programme. Thanks partly to congressional supervision, NASA has not raided its science account to pay for the space shuttle or the space station. Spending on science has actually gone up, while the shuttle and space-station budgets have stayed flat or declined.

Scientists believe, with good reason, that this is based largely on merit. The Hubble Space Telescope, the Wilkinson Microwave Anisotropy Probe and the Mars Exploration Rovers have returned solid results. The shuttle and space station have not.

Now, however, NASA faces more fiscal pressure than at any time in recent memory. Fixing the shuttle will, predictably, be more expensive than NASA first thought. The latest estimate is $\$ 1.15$ billion, plus the cost of added safety once the vehicle is flying again. Administrator Sean O'Keefe's decision to bar astronauts from visiting Hubble again has pinned the telescope's fate to an expensive robotic repair mission. Cost estimates vary wildly but start at about $\$ 1.3$ billion.

Looming even larger is President Bush's 'Vision for space exploration', which would send astronauts back to the Moon and on to Mars. No one is sure what this will cost, but the Congressional Budget Office recently guessed at $\$ 127$ billion by 2020 . NASA wants to start next year, with $\$ 438$ million requested for the Crew Exploration Vehicle.

The White House and NASA sold the exploration programme on the basis that it would require no large increase in funding - the money would come from retiring the shuttle and the space station. It is a sensible plan but may already be unravelling. A report released last week by the National Academy of Sciences showed how just one area of science — solar and space physics — could be affected by the "more constrained funding climate" that would accompany a Moon-Mars programme. A sequence of missions could delay highpriority projects such as the proposed Solar Probe for years.

Fortunately, Congress is watching. Last week the Senate appropriations committee cut NASA's $\$ 16.2$ billion request by $\$ 664$ million, including projects associated with the exploration programme. An additional $\$ 800$ million in emergency spending would go to solve the shuttle and Hubble problems. More importantly, the committee directed NASA not to upset the balance of its science programme to fund the Moon-Mars effort. The House appropriations committee, which made even deeper cuts to the exploration programme this summer, was more blunt, writing: "While the Committee is supportive of the exploration aspect of NASA's vision, the Committee does not believe it warrants top billing over science and aeronautics."

Bush's Vision has failed to wow either the media or the general public. NASA should stick to its original plan to pay for the MoonMars programme from within its existing spaceflight account. If the shuttle or space station have financial setbacks, the Vision should be scaled back or delayed. But hands off the science programme, which today is doing the real exploring in space.

\section{Open-source biology}

Researchers and entrepreneurs alike should welcome a move to develop a new commons in technological innovation.

W ith the research community increasingly frustrated by a growing forest of patents around innovations in the biological sciences, an initiative to make research tools from the life sciences open-source deserves to acquire some traction.

The Biological Innovation for Open Society (BIOS) initiative (see page 494) makes a distinction between tools and applications of innovation. Its champions argue that research tools should be freely available, much as operating systems, programming languages and standards are shared by the open-source software community.

The ranks of those wanting to see more put back into the life sciences for the public good are swelling. There is discontent that innovations from publicly funded scientists are being sold off to private companies and locked up in exclusive licensing. Concern is mounting that poorer nations are being further disenfranchised by richer countries' ownership and control of enabling technologies. Even purely academic scientists are not immune from the effect of licensing obstacles on new techniques.

BIOS should help on several fronts (see www.bios.net). Its intellectual-property database and associated informatics promise to bring more transparency to the opaque patent web and to provide tools to guide decision-making when choosing technologies. It will provide a suite of licences and other contract mechanisms for contributors to make their research tools available to a protective commons. And it will provide an Internet-based mechanism to bring networks of researchers together to cooperate on specific technology development projects.

But are biologists ready for an open-source revolution similar to that which spurred information technology? The development of biological tools involves years of research and investment. And, in some cases, it's not as simple as downloading software, with potential logistical challenges involving the transfer of materials and issues of liability. But if BIOS can overcome these challenges, as its champions say it can, it offers a novel means for biologists to share research tools.

As its creators acknowledge, the success of BIOS hinges on active community participation — it needs a large network of scientists to devote their time to contributing research tools, sharing knowledge and addressing particular technology needs. It also needs financial support from private and public benefactors. If the opensource software movement is any guide, there will be willing backers of competitive open-source technologies — as exemplified by IBM's support of the Linux operating system.

The ultimate question is whether BIOS will benefit those for whom it is most intended and provide technology access to the poor and excluded. Whatever the outcome, it deserves a chance to garner support from the research community. At the veryleast, it may inspire other open-source initiatives within the biological sciences. 